\title{
Integrating adolescent livelihood activities within a reproductive health program for urban slum dwellers in India
}

\author{
Dale Huntington \\ Mary Philip Sebastian \\ Population Council \\ Nirmala Sevlam \\ Barbara Mensch \\ Population Council \\ Sahar Hegazi
}

Follow this and additional works at: https://knowledgecommons.popcouncil.org/departments_sbsr-rh

Part of the Demography, Population, and Ecology Commons, Health Services Research Commons, International Public Health Commons, and the Vocational Education Commons How does access to this work benefit you? Let us know!

\section{Recommended Citation}

Huntington, Dale, Mary Philip Sebastian, Nirmala Sevlam, Barbara Mensch, and Sahar Hegazi. 2001.

"Integrating adolescent livelihood activities within a reproductive health program for urban slum dwellers in India," FRONTIERS Update. New Delhi: Population Council. 


\section{Integrating Adolescent Livelihood Activities within a Reproductive Health Program for Urban Slum Dwellers in India}

T

he limited number of policies and programs directed towards adolescent girls in India are mainly confined to the health sector. Proponents of adolescent policy have stressed the health consequences of early sexual activity and pregnancy to adolescents and the larger society. Little attention has been paid to preparing girls for future livelihoods and fostering their social mobility. Yet legitimate income-generating work is likely to transform girls' adolescent experiences by providing them with a degree of autonomy and freedom from traditional gender roles. Most importantly, it should help to reframe the second decade of girls' lives from a period devoted to preparation for marriage and childbearing to a time when they can develop as individuals and gain knowledge and skills for a more productive adulthood. In addition, it should provide girls, who are often confined to the home with heavy domestic responsibilities, with a degree of mobility and with networks and peer support groups outside the family. Work has the added benefit of offering girls an alternative source of

\section{Population Council}

social status that is likely to delay marriage. It is hypothesized that girls who contribute income to the household have greater control over their sexual and reproductive lives (Bruce and Mensch 1999; Mensch, Bruce and Greene 1998).

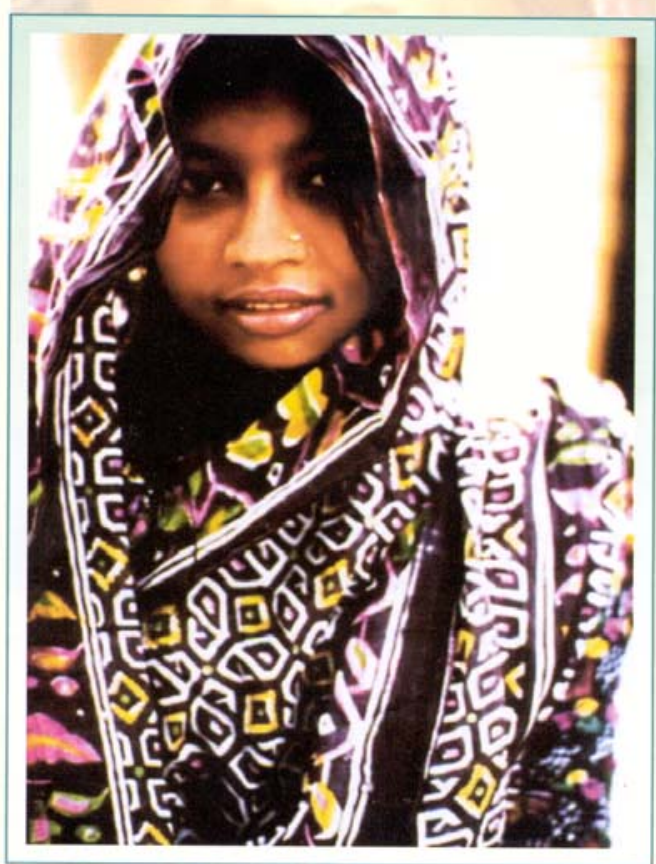

Frontiers 


\section{Project Update}

The rationale for developing livelihood programs for girls is particularly applicable to India where over one-quarter of girls are married by age 15 and over one-half by age 18, and where over one-third of 13-16 year olds and nearly two-thirds of 17-19 year olds are mothers or are pregnant with their first child (Jejeebhoy 1996). In addition, there are dramatic gender disparities among adolescents in educational attainment and literacy. About onethird of girls 15-19 complete middle school compared to over one-half of boys, and 56 percent of girls are literate compared to 81 percent of boys. Mortality rates among adolescent girls are 25-50 percent higher than among boys; nutritional deficits are greater and access to health care lower (Jejeebhoy 1996). In short, adolescent girls in India are particularly disadvantaged in comparison to boys.

CARE India began a pilot project four years ago in 65 slum areas of Allahabad that created reproductive health services for approximately 28,000 disadvantaged adult women. Allahabad district is located in India's most populous state of Uttar Pradesh and has an estimated population of 800,000 . In the rural areas of Allahabad district, lower castes generally work as bonded labor, and the upper castes possess most of the land. The lack of livelihood opportunities in the rural areas drives many families to migrate to Allahabad city. The rural migrants live in overcrowded slums with poor hygiene and sanitation and experience the many social problems associated with extreme urban poverty.
The CARE India pilot project was renewed for five years starting in July 1999 (funding by DFID). This new project, Action for Slum Dwellers Reproductive Health, Allahabad (ASRHA), puts young women's reproductive health issues at the center of a development approach that recognizes the competing needs of about 66,000 adolescents boys and girls (aged 10-19 years) and about 45,000 women (aged 20-49) in 143 slum areas. The CARE India strategy takes as its starting point the low priority status of women's reproductive health concerns and works to demonstrate that multiple

\section{CARE India's ASRHA Project}

The principal activities of the ASRHA project include:

- Forming a network of adolescent peer educators and neighborhood community centers

- Implementing a mass media / enter-educative campaign

- Competency-based training of public and privatehealth care providers

- Strengthening existing health delivery system

- Training of traditional birth attendants

- A women's health center providing a broad range of reproductive and child health services, family planning and referral services

- Building the capacity of local women's groups and adolescents to manage health and development needs

- Linkages with other NGOs and community support groups

- Information dissemination 
benefits accrue from reproductive health care activities, particularly when community participation and local capacity building activities are emphasized.

The Population Council's Frontiers in Reproductive Health Program and the Policy and Research Division are collaborating with CARE India to conduct an operations research (OR) study with the goal of examining the feasibility and impact of adding livelihood counseling and training, savings formation activities, and follow-up support to the on-going reproductive health program for adolescents. The short-term objective of the study is to foster the development of alternative socialization processes for adolescent girls that encourage positive sexual and reproductive health behaviors. The study will also produce a replicable model for CARE India and other agencies to use in adding livelihood activities to adolescent reproductive health programs.

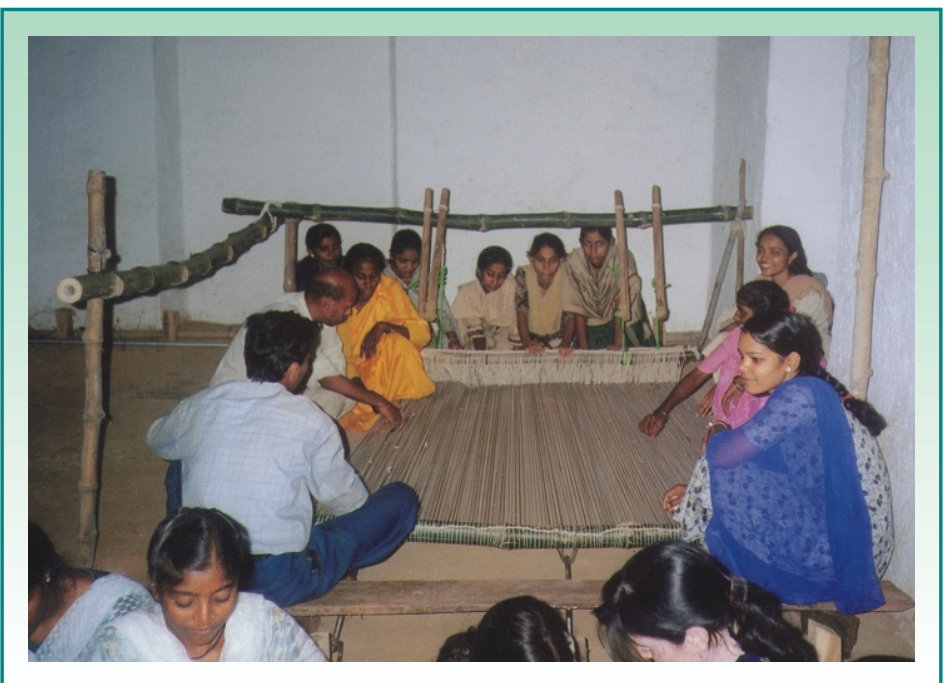

The OR project's principal immediate outcome indicators include:

Vocational knowledge and awareness

- Attitudes towards gender roles

Specific knowledge of vocational training and procedures for participation

- Skill development and livelihood activities

- Savings activities

- Time use

- Physical mobility within the community

- Participation in reproductive health peer group organizations

- Contact with non-family members (quality and quantity)

Work aspirations

Attitudes toward conflicts between work, family roles and responsibilities

\section{Study Design}

The study uses a quasi-experimental, pre- and post-test study design that compares the intervention group with a control group of adolescents. A baseline and endline survey (separated by an intervention period of 12 months) of all adolescents and one of their parents will measure the differential effects of exposure to the various elements of the intervention. A mid-term follow-up interview with adolescents who participated in one or more of the vocational training sessions and savings formation activities will capture immediate effects of the experimental 


\section{Project Update}

intervention. Case studies will be produced based on the experiences of adolescents who participated in different aspects of the intervention and those who did not. The intervention is being implemented in five slums. Nine slums form the comparison area. Both study groups are selected from the CARE India ASRHA project sites, and all of the adolescents living in the study groups' slum areas are eligible to participate in the CARE India ASRHA project. Approximately 1,000 adolescent girls live in each of the study group areas and all will be interviewed in the two surveys, in addition to one of their parents and all of the boys living in the same areas.

The Adolescent Livelihoods project began in January 2001 and will continue for 30 months until June 2003. Indicators relating to the immediate outcomes will be used as measurements for the study. Both qualitative and quantitative methods will be used to assess the indicators, yet impact will be measured by quantitative methods only. Many of the changes in behavior (such as increases in confidence and mobility due to the study's intervention activities) will be assessed through case studies. This Project Update reports on the

\section{The OR Study Intervention}

The study's experimental intervention is based on the following elements:

1. Counseling about livelihoods, vocational training and savings formation
2. Vocational training courses

3. Supportive follow-up counseling and as sistance

The counseling on vocational training and livelihoods formation provides information about short-term, non-formal training courses available in the vicinity that are being organized under the auspices of the project, including courses offered by various government institutes and NGOs as well as courses organized specifically by the project (these courses are described more fully below). Interested girls are assisted to participate in several ways that include helping them to complete application forms, having project staff speak to a parent about the course, and even contributing to her payment of course fees. The project provides follow-up supportive counseling to adolescents who have received vocational training or who are interested in setting up some type of savings activity. This counseling includes developing action plans for beginning a livelihood activity and beginning savings.

\section{Key Elements of the Study's Intervention}

The Population Council's intervention uses the same strategy as CARE India to reach out to the adolescents in the community through Adolescent Girl Guides (AGGs) who act as peer educators and provide counseling about vocational training and savings formation. In the ASRHA project the AGGs 


\section{Paro Flipbooks}

The Paro story used in the reproductive health training sessions cover the following content in the five flipbooks:

Book 1: Physiological and behavioral changes at onset of puberty.

Book 2: Menstruation and vaginal discharge and infection.

Book 3: How a baby is formed, sex of the fetus, pregnancy and birth.

Book 4: Right age of marriage, birth spacing and care during pregnancy.

Book 5: Family planning, role of the husband, and family planning methods: condoms, IUD, pills and sterilization.

are chosen from the slums and given a six-day reproductive health training course by CARE India staff that includes guidance and practice to improve their communication skills. Only adolescent girls who can read and write and are willing to bring together other adolescent girls in the slum are chosen as AGGs to conduct the reproductive health education sessions using specially developed storybooks. The story-books are educational materials in the form of flip charts that relate the experiences of a typical 12-year-old adolescent girl named Paro as she learns about her reproductive health. The story is presented in a set of five flipbooks in Hindi, which are referred to as the Paro flipbooks. The AGGs (two or three per slum) are responsible for forming groups in the slums and leading Paro classes. To the extent it is possible CARE India staff are present in these meetings to help the AGGs in their task of

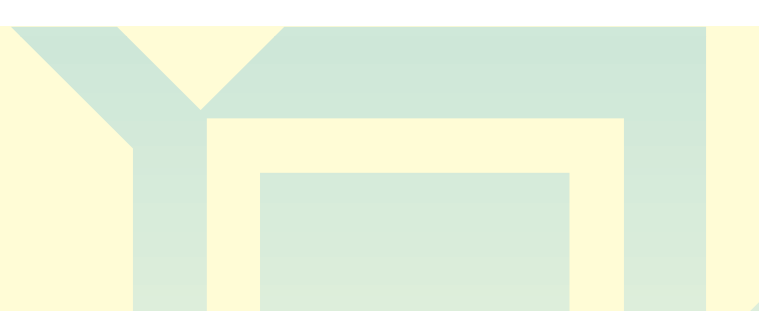

educating the girls. Usually weekly meetings are held at the residence of one of the AGGs in the slum. One Paro flipbook is completed in each session. Each session takes approximately 1-2 hours depending on the participation from the girls and the questions asked by them.

Additional peer educators, who are able to read and write and have attended all the Paro sessions led by an AGG, are selected by CARE India staff to reach the girls who do not attend the meetings. These "assistant peer educators" support the more intensive group-work of the AGGs. All of the assistant peer educators receive a three-day training on reproductive health and how to use reproductive health leaflets when talking to other adolescent girls as a type of one-to-one counseling model. The recruitment, training and initial work of the AGG and assistant peer educators preceded the introduction of the operations research study.

\section{Preparing the Intervention}

The first step in developing the intervention was to collect information on all of the vocational training courses available in Allahabad. The inventory of all vocational courses revealed a wide range of skill and livelihoods building courses that lasted anywhere from one week to almost a year. The inventory list contained vocational training courses that could be conducted either by a government institute or by a local NGO involved in development programs. Courses were excluded that 


\section{Project Update}

required an investment in expensive capital equipment or were considered inappropriate for adolescent girls from the slums. A final short list of 21 courses was developed that includes government-sponsored courses such as food preservation training conducted at a nearby food and nutrition training center, and other courses held at the Government Women's Polytechnic Institute. However, the majority of the vocational training courses are given by local NGOs and organized by the study team. For example, some of the study sites are located near factories that can offer home-based employment opportunities (e.g., micro light bulb filament making and assembly, silver links for jewellery and rug/dhari weaving).

For most of the courses a minimal investment is needed to purchase training equipment and supplies. After the training, some materials are required for the production of the handicrafts at home. Initially the project provides some of this capital investment (e.g., handlooms for dhari weaving classes and subsidized materials used for sewing or weaving). Participants contribute a small

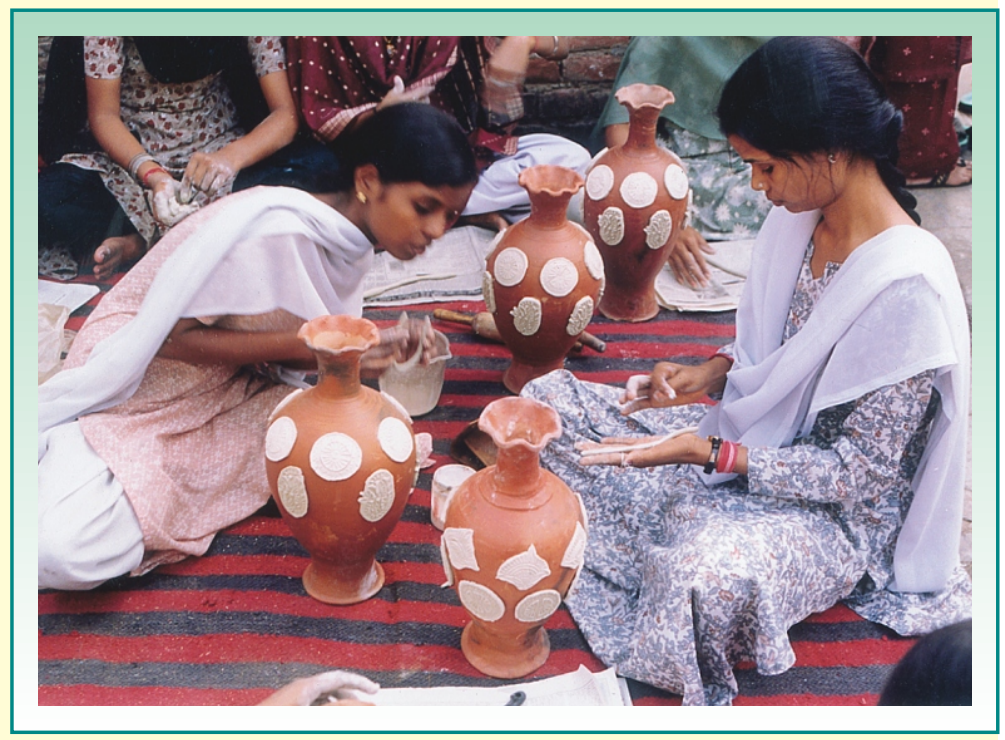

amount towards the purchase of raw materials for their respective courses. Once the trainees reach a level of competence they will be given work by the NGOs (to the extent that such commissions are available). For example, an NGO will supply a trained girl with raw material and pay her around Rs. 50 per square yard for a dhari that she weaves, using skills learned in the course and a loom made available through the project. Other common types of outcomes from the training are making silver links or light bulb filaments that can generate an income of Rs. 25-50 per day.

The project identified sites for the training and course instructors. Project staff selected course instructors to prepare the courses (e.g., review operational details, including arranging transportation to and from the training site if the training is conducted outside the slum area). Some of the courses are being held at a nearby training institute run by the Diocesan Development and Welfare Society (DDWS) through locally hired trainers. Courses like mehndi painting are being conducted in the slums by locally hired trainers whose work is considered good and who can work with adolescents. The dates and venue for each course are fixed and the adolescents are informed through the AGGs. The project purchases bulk supplies of raw materials (e.g., bolts of cheap cotton fabric for sewing classes) from wholesale shops to keep the cost as low as possible. The project arranged transportation for all courses where participants have to leave their slums to attend training centers in the city. 


Vocational Courses
1. Mehndi
2. Creative painting
3. Mending and embroidery
4. Pot decoration
5. Dhari weaving
6. Tailoring
a. Part 1 : cutting and hand sewing
b. Part 2 : machine sewing
7. Candle making
8. Crochet
9. Basic cooking
10. Macrame
11. Miniature bulb filament mounting
12. Silver ornament links
13. Jute craft
14. Jute dolls
15. Jute bag making
16. Personal grooming
17. Fabric painting
18. Block printing
19. Soft toys
20. Beekeeping
21. Food preservation

\section{Training AGGs in Counseling} about Livelihoods and

\section{Savings Formation}

The operations research project provided additional training for the AGGs and their assistants

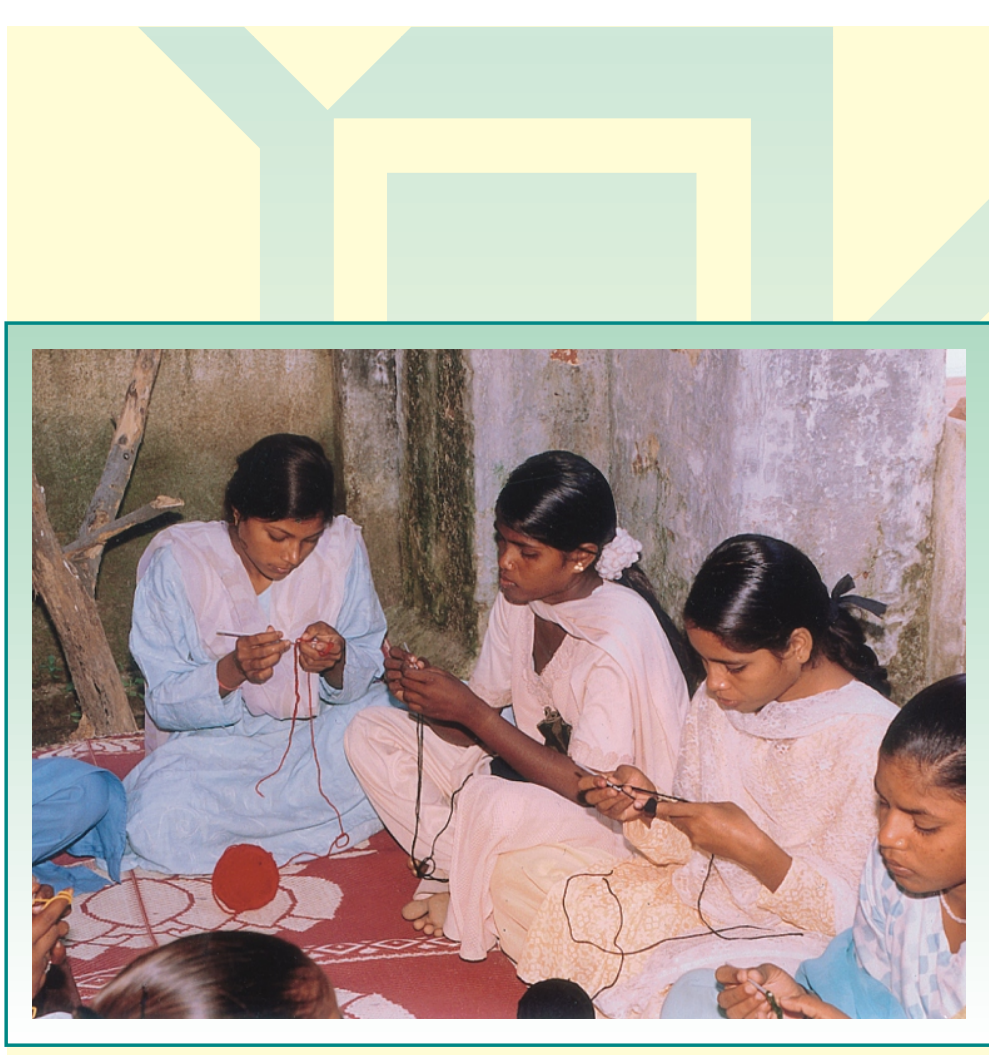

in counseling about livelihoods and savings formation. These training courses were conducted after the CARE India adolescent reproductive health project had been in operation a short while, and were organized as a series of short-term courses. The first batch of training courses was held in two one-day training sessions on consecutive Sundays in July 2001. Twenty-one AGGs from the ten existing groups in the five experimental slums were trained to provide counseling about vocational training courses and savings formation activities. An additional eight assistant peer educators (who were selected from the adolescent reproductive health groups) were also trained. A second batch of training courses will be held in late November for the AGGs and assistant peer educators recruited by the CARE India project in August-October. With the completion of the second training program the project will have successfully involved all of the AGGs and their assistants in the livelihoods program. 


\section{Project Update}

The objectives of the AGG training courses were to:

- Orient the AGGs and assistant peer educators about vocational training opportunities in the project.

- Orient the AGGs and assistant peer educators about savings information.

- Enable AGGs and assistant peer educators to serve as communicators and facilitators in their respective slums.

The training sessions for AGGs and the assistant peer educators were facilitated by the study team and consultants. The courses were highly participatory and used methods such as games, group discussions, role-plays and demonstrations. Each AGG and assistant peer educator received a flipbook containing vocational flash cards to guide them in describing the vocational courses available to the girls in their neighborhood. The AGGs and assistant peer educators practiced talking to their peers about vocational training courses using the flipbook and other materials. Some of the participants were confident while others were still shy and needed

\section{Topics Covered during Training}

Objectives of the workshop

- Vocational training in the $O R$ project and the courses offered by the project

- Importance of savings and ways to save

- Role of AGG in the Adolescent Livelihoods project

- How to use IEC materials to communicate with peers and parents
Role-Play Scenario

A middle aged couple is presented where the husband's job is not secure, the wife does regular housecleaning jobs to earn money, and they have three unmarried teenaged children a son aged 17 , and two daughters aged 16 and 15 years. The three adolescents are excited about the opportunities to develop some income generation or livelihood skills and seek their parents' permission to go for training. The parents are trying to decide how to manage the course fees within their limited resources.

more practice. The topic on savings formation was discussed in detail. The participants in the training courses themselves were very interested in the topics and were keen to open their own savings accounts. Many were not aware that they could open and operate their own accounts. Others wanted to take part in the vocational training courses.

Role-plays were used to demonstrate how people make decisions by looking at all available alternatives, analyzing the alternatives and choosing one of them. It was interesting for many of the participants to try to consider decisions from their parents' perspectives. One notable point in the role-plays occurred when the trainee was playing the role of the parent. In this role the AGGs were more supportive of their daughters than their sons and attempted to budget the family income in such a way that their daughters could attend the vocational courses. 


\section{Working through Obstacles}

\section{Parents' fears about the safety of their}

adolescent daughters. Initially, in most of the slums the parents agreed to send their daughters for vocational training if someone from the slum agreed to accompany them to the training site and back. However, during the reproductive health training sessions organized by the CARE India project one of the AGGs ran away from home with her boyfriend. After this incident the chaperone from the slum where this incident took place said she could manage the supervision of only small groups of girls. In other slums parents were not ready to send their daughters to activities outside of their neighborhoods.

\section{Fear that the vocational courses would not be}

completed. Due to the premature closure of a previous vocational course in the slums, many girls and parents worried that the course might be discontinued before the girls could finish. Project staff had to reassure the community that courses would continue until completion.

In consideration of these concerns and other misapprehensions, the project team decided to begin with short-term courses provided in the slums before moving to longer courses offered in nearby areas of the city. The project team chose one-week courses that had the additional benefit that they could be conducted in the houses of the residents. Another consideration was to begin with courses that developed skills that are immediately visible to the parents and girls. The phased manner of introducing courses, flexibility in arranging the sites for the training and careful selection of courses with a good likelihood of impact helped build trust within the community for the Adolescent Livelihoods project.

Regulations Governing Savings Accounts

Anyone above 10 years of age can open a savings account in a bank without a parent or guardian. Anyone above 14 years can have a current account also. Opening a savings account in a bank requires a $R$ s. 500 initial deposit and minimum balance. With just Rs. 20 as an initial deposit and minimum balance, anyone above 10 years of age can open and operate a savings account in the post office.

\section{On-Going Efforts}

Savings. After the first round of training programs for AGGs and assistant peer educators, the project staff began counseling adolescent groups about savings. This resulted in an almost universal demand to open a savings account. Mos of the adolescents who attended training sought out and received permission from parents to open a postal savings account. The central post office issued an identity card to one of the project staff so that she could assist girls in opening accounts at the local post offices. Five adolescents from each slum 


\section{Project Update}

in the experimental group opened accounts at local post office almost immediately. Another 25 adolescents began the application process soon after, and many other girls are currently in the process of completing the formalities to open their accounts.

Vocational training courses. The first set of vocational training courses began in August and included mehndi, creative painting, pot decoration, mending and embroidery. Adolescent girls who attended regularly and completed the CARE project courses on reproductive health were asked to complete an application form and prioritize their interests in the four courses. Mehndi and painting emerged as top priorities. Each girl was allowed to attend only one course during this first phase of the project. For school-going girls, vocational training sessions were arranged on Sundays. Those who were not school-going attended training during the week. The girls impressed their parents as well as the course trainers with their ability to master the skills taught to them.

The modest admission fees and cost of materials and supplies for the vocational training courses are subsidized by the project. Eligible adolescent girls pay Rs. 10 for one-week courses and Rs. 25 for courses that last one month or longer. Participants also share the cost of raw materials used in the course.

The second set of courses began in September and included (in addition to the other courses that were offered in the first session): dhari weaving and tailoring part 1: cutting and hand sewing. These courses take place in the city and transportation to and from the training site was arranged by the project. The transportation plan is working well and enthusiasm and cooperation from the parents seems quite high. Parents are now willing to send their daughters to vocational training courses without an adult accompanying them and demand is growing for more girls to attend vocational training courses.

\begin{tabular}{|l|c|c|c|}
\hline \multicolumn{4}{|c|}{ Attendance for Vocational Training Courses in the ORProject (On-going) } \\
\hline $\begin{array}{c}\text { Name of vocational } \\
\text { training course }\end{array}$ & $\begin{array}{c}\text { Course } \\
\text { Duration }\end{array}$ & $\begin{array}{c}\text { Number completed } \\
\text { the course }\end{array}$ & $\begin{array}{c}\text { Number currently } \\
\text { enrolled }\end{array}$ \\
\hline Mehndi & 6 days & 136 & 15 \\
\hline Creative painting & 6 days & 88 & 15 \\
\hline Dhari weaving & 1 month & 22 & - \\
\hline Tailoring part 1 & 3 months & - & 12 \\
\hline Mending and embroidery & 15 days & - & 10 \\
\hline Candle making & 6 days & 48 & 12 \\
\hline Silver ornament links & 6 days & - & 15 \\
\hline Pot decoration & 6 days & - & 13 \\
\hline Crochet & 1 month & - & 132 \\
\hline Jute dolls & 6 days & - & 294 \\
\hline Total number of girls trained & & & \\
\hline
\end{tabular}




\section{Conclusion}

The intervention, which includes vocational counseling, vocational training, follow-up support and savings activities, has begun its operations in the five experimental slums. Thus far the project has demonstrated that it is feasible to provide shortterm, non-formal training in vocational skills to adolescent girls living in the slums of Allahabad, and that such training can be successfully integrated within the CARE India ASRHA project's activities. A modest input of resources is required for these training courses, but so far the experience has shown that community members are willing to contribute to the costs of these courses and to permit their girls to travel outside the slum areas to take part in the training. The girls who take part in the courses also see the training as an opportunity to socialize with their peers and to find some time to relax. The girls usually stay after the vocational training sessions singing, dancing, talking and sharing experiences. Though the parents initially resisted sending the girls to these meetings, they

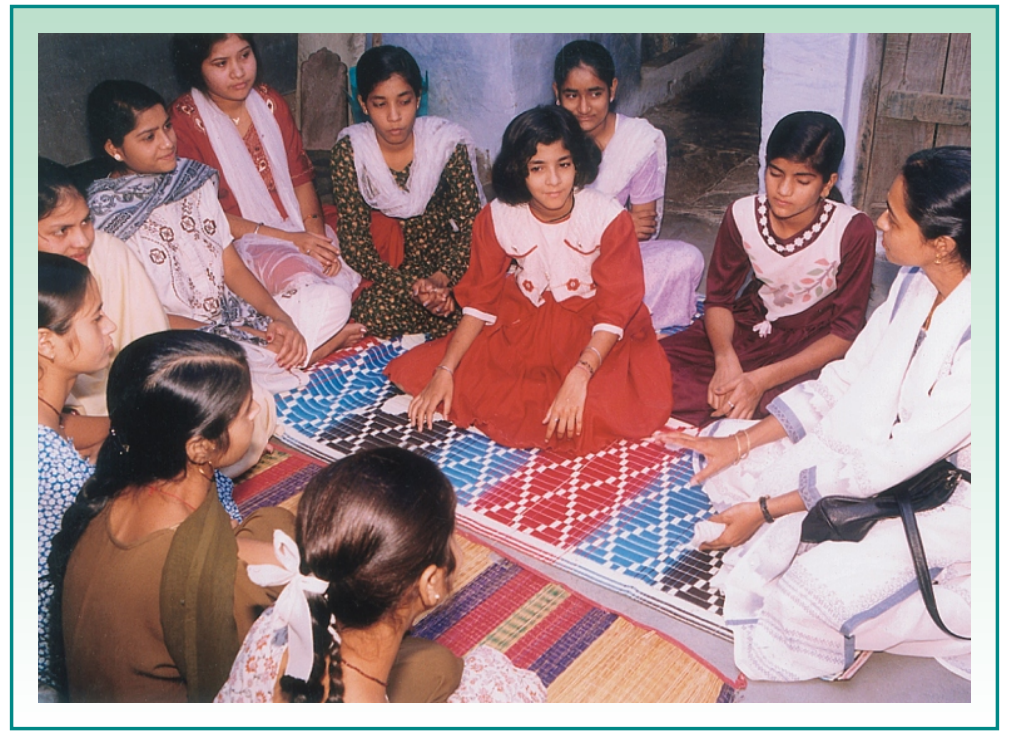

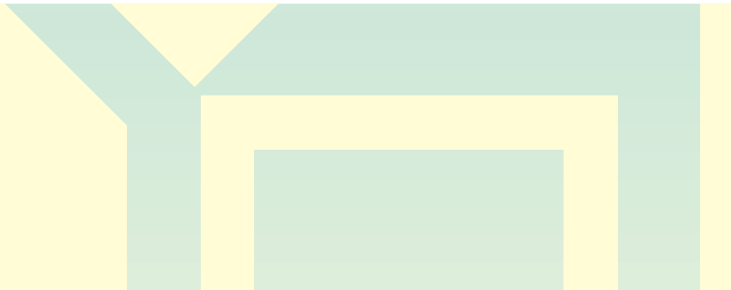

realized that these meetings are useful for the growth and development of their daughters. The experience with savings formation has shown that with a facilitator's advice, adolescent girls are able to open postal savings accounts. The management of these accounts and their usefulness still needs to be evaluated.

The initial restrictions on girls' mobility are now being relaxed and perhaps the parents in the slum areas will also relax other restrictions placed on the girls' opportunities to socialize outside of the home. After only two months of working with the adolescent groups, changes in the attitudes and behavior of the parents have been observed, and the girls (particularly those who are illiterate) appear to have gained more self-confidence and interact more actively in group work. Girls who have completed the first round of vocational training courses (e.g., mehndi and creative painting) are already earning income from selling their services or products. This has not gone unnoticed by the other residents in the project sites and many other girls and their parents are now approaching the staff of the Population Council and CARE with requests for admission to vocational training courses. 


\section{Project Update}

\section{References}

Bruce, Judith, and Barbara S. Mensch. 1999. "Taking Back Young Lives: Policy Issues for Adolescent Girls in the Developing World." Journal of the American Medical Women's Association Vol. 54, No. 3:153-154, 160.

Jejeebhoy, Shireen J. 1996. "Adolescent Sexual and Reproductive Behaviour: A Review of Evidence from India." ICRW Working Paper No. 3, December 1996. Washington D.C.: International Center for Research for Women.

Mensch, Barbara S., Judith Bruce, and Margaret E. Greene. 1998. The Uncharted Passage: Girl's Adolescence in the Developing World. New York: The Population Council.

\section{Contributors}

Dale Huntington, Sc.D.

Mary Philip Sebastian, Ph.D.

Nirmala Selvam, PGDPR

Barbara Mensch, Ph.D

Sahar Hegazi, M.A.

\section{Editor}

Chris Parker
November 2001

This publication was made possible through support provided by the Office of Population, Health and Nutrition of the United States Agency for International Development (USAID), under the terms of Cooperative Agreement Number HRNA-00-98-00012-00. The opinions expressed herein are those of the authors and do not necessarily reflect the views of USAID.

For more information on this study please contact Dale Huntington, Frontiers in Reproductive Health, Population Council, 53 Lodi Estate, New Delhi 110 003, India.

Tel: (91-11) 461-0913

Fax: (91-11) 461-0912

E-mail: frontiers@pcindia.org 